terior surfaces of the flasks, but in the body of the infusions themselves.

By this method I tested in the first place the substance which, at an early stage of the inquiry, had excited my suspicion-without reference to which the discrepancy between the behaviour of infusions examined in the winter of $1875-76$ and those examined in the winter of $1876-77$ is inexplicable, but by reference to which the explanation of the observed discrepancy is complete-I mean the old hay which cumbered our laboratory floor.

Four hours' continuous boiling failed to sterilise bulbs charged with infusions of this old hay. In special cases, moreover, germs were found so indurated and resistant, that five, six, and in one case even eight hours' boiling failed to deprive them of life. All the difficulties encountered in this long and laborious inquiry were traced to the germs which exhibited the extraordinary powers of resistance here deseribed. They introduced a plague into our atmosphere-the other infusions, like a smitten population, becoming the victims of a contagium foreign to themselves.

It is a question of obvious interest to the scientific surgcon whether those powerfully resistant germs are amenable to the ordinary processes of disinfection. It is perfectly certain that they resist to an extraordinary extent the action of heat. They have been proved competent to cause infusions, both animal and vegetable, to putrefy. How would they behave in the wards of a hospital? There are, moreover, establishments devoted to the preserving of meats and vegetables. Do they ever experience inexplicable reverses. I think it certain that the mere shaking of a bunch of desiccated hay in the air of an establishment of this character might render the ordinary process of boiling for a few minutes utterly nucratory, thus possibly entailing serious loss. They have, as will subsequently appear, one great safeguard in the complete purgation of their sealed tins of air.

Keeping these germs and the phases through which they pass to reach the developed organism clearly in view, I have been able to sterilise the most obstinate infusions encountered in this inquiry by heating them for a minute fraction of the time above referred to as insufficient to sterilise them. The fully developed Bacterium is demonstrably killed by a temperature of $140^{\circ} \mathrm{F}$. Fixing the mind's eye upon the germ during its passage from the hard and resistant to the plastic and sensitive state, it will appear in the highest degree probable that the plastic stage will be reached by different germs in different times. Some are more indurated than others and require a longer immer. sion to soften and germinate. For all known germs there exists a period of incubation during which they prepare themselves for emergence as the finished organisms which have been proved so sensitive to heat. If during this period, and well within it, the infusion be boiled for even the fraction of a minute, the softened germs which are then approaching their phase of final development will be destroyed. Repeating the process of heating every ten or twelve hours, and before the least sensible change has occurred in the infusions, each successive heating will destroy the germs then softened and ready for destruction, until after a sufficient number of heatings the last living germ will disappear.

Guided by the principle here laid down, and applying the heat discontinuously, infusions have been sterilised by an aggregate period of heating, which, fifty times multiplied, would fail to sterilise them if applied continuously. Four minutes in the one case can accomplish what four hours fail to accomplish in the other.

If properly followed out the method of sterilisation here described is infallible. A temperature, moreover, far below the boiling point suffices for sterilisation.

Another mode of sterilisation equally certain, and per-

I A hard and wiry hay from Guildford, which I have no reason to consider old, was found very difficult to sterilise. haps still more remarkable, was forced upon me, so to speak, in the following way :-In a multitude of cases a thick and folded layer of fatty scum, made up of matted Bacteria, gathered upon the surfaces of the infusions, the liquid underneath becoming sometimes cloudy throughout, but frequently maintaining a transparency equal to that of distilled water. The living scum-layer, as Pasteur has shown in other cases, appeared to possess the power of completely intercepting the atmospheric oxygen, appropriating the gas and depriving the germs in the liquid underneath of an element necessary to their development. Above the scum, moreover, the interior surfaces of the bulbs used in my experiments were commonly moistened by the water of condensation. Into it the Bacteria sometimes rose, forming a kind of gauzy film to a height of an inch or more above the liquid. In fact, wherever air was to be found, the Bacteria followed it. It seemed a necessity of their existence. Hence the question, What will occur when the infusions are deprived of air?

I was by no means entitled to rest satisfied with an inference as an answer to this question; for Pasteur, in his masterly researches, has abundantly demonstrated that the process of alcoholic fermentation depends on the continuance of life without air-other organisms than Torula being also shown competent to live without oxygen. Experiment alone could determine the effect of exhaustion upon the particular organisms here under review. Air-pump vacua were first employed, and with a considerable measure of success. Life was demonstrably enfeebled in such vacua.

Sprengel pumps were afterwards used to remove more effectually both the air dissolved in the infusions and that diffused in the spaces above them. The periods of exhaustion varied from one to eight hours, and the results of the experiments may be thus summed up :--Could the air be completely removed from the infusions, there is every reason to believe that sterilisation zeitiout boiling would in most, if not in all cases, be the result. But, passing from probabilities to certainties, it is a proved pact that in numerous cases unboiled infusions deprived of air by five or six hours' action of the Sprengel pump are reduced to permanent barrenness. In a great number of cases, moreover, where the unboiled infusion would have become cloudy, exposure to the boiling temperature for a single minute sufficed completely to destroy the life already on the point of being extinguished through defect of air. With a single exception, I am not sure that any infusion escaped sterilisation by five minutes' boiling after it had been deprived of air by the Sprengel pump. These five minutes accomplished what five hours often failed to accomplish in the presence of air.

The inertness of the germs in liquids deprived of air is not due to a mere suspension of their powers. They are killed by being deprived of oxygen. For when the air which has been removed by the Sprengel pump is, after some time, carefully restored to the infusion, unaccoinpanied by germs from without, there is no revival of life. By removing the air we stifle the life which the returning air is incompetent to restore.

\section{AGRICULTURAL EXPERIMENTS AT WOBURN}

I $\mathrm{N}$ the autumn of $\mathrm{I} 875 \mathrm{Mr}$. C. Randell proposed to the Council of the Royal Agricultural Society that it be referred to the Chemical Committee to consider the propricty, and the manner, of instituting a series of experiments, to test the accuracy of the estimated value of manure obtained by the consumption of different articles of food, as given in Mr. Lawes' paper, in the Spring Number of the Journal of the Society.

$\Lambda \mathrm{s}$ it was decided that experiments by practical farmers in different districts could not, be relied on, the Dute of 
Bedford very kindly offered to afford facilities for making new experiments at his own cost.

Mr. Lawes and Dr. Voelcker were requested to draw up a scheme for carrying on, at Woburn, such experiments as they, in communication with the Chemical Committee, might determine on. His grace offerea to give up for the purpose Crawley Mill Farm, comprising about ninety acres, with the house and buildings. But, on examination, it was found that there vras no sufficient area on that farm so even in character, and in condition, of soil, as to render it available for a considerable series of comparative field experiments. Eventually, after inspection of many others, a large field of much more suitable land was selected; on Birchmoor Farm. Crawley Mill Farm is, however, also retained, as a means of providing a residence for the Superintendent of the experiments, the requisite buildings, and the opportunity of having at command the necessary horse and hand labour for the experiments. Mr. P. H. Cathcart, formerly at the Royal Agricultural College, Cirencester, has been appointed the Resident Superintendent of the experiments.

As experiments to determine the value of the manure obtained by the consumption of purchased foods obviously involved the necessity of feeding animals under conditions in which the manure could be collected with as little loss as possible, the Duke of Bedford has erected eight very complete feeding boxes, in which the manure for the experimental barley and root crops recently sown has been made.

The field devoted to the field experiments has an area of twenty-seven acres; the soil has been carefully tested ail over, and an account taken of the bistory of the field since 1874 .

It was considered imporiant, especially with reference to valuations under the Agricultural Holdings' Act, to add, if possible, to our knowledge of the manure-value of both artificial manures and consumed feeding stuffs; and it was decided, therefore, both to compare the effects of the manure obtained by the consurnption of selected purchased foods, with those obtained by artificial manures estimated to supply the same constituents, and also to determine the effects of dung and artificial manuring substances, applied year after year, on the Woburn soil, and to compare these with the results obtained for so many years, with the same manures, on the very different soil at Rothamsted. Accordingly, $2 \frac{3}{4}$ of the six acres where wheat had been grown in 1876 , after tares and turnips, each fed with cake, are devoted to the continuous growth of wheat, and 2 acres to the continuous growth of barley. In each case the area is divided into eleven plots, of a quarter of an acre each.

The description and quantities of the manures for these experiments have been so carefully selected that in the end valuable results must be obtained as to the comparative value of various kinds of artificial manure as compared with farmyard manure, the constituents of which are accurately known. Two of the plots are unmanured; seven are manured with artificial manure of more or less complicated composition, and two with farmyard manure estimated to contain different proportions of nitrogen. In connection with the farmyard manure an accurate record is kept of the kinds and quantities of food from which it is produced, as also of the increase in the live-weight of the stock thus fed.

Besides these continuous experiments a series of rotation experiments - seeds, wheat, roots, barley, in successive years from $\mathrm{I} 877$ to $\mathrm{I} 88 \mathrm{I}$-are to be carried out. The stock which is to supply the farmyard manure for these experiments is to be fed with decorticated cotton-cake, which among purchased feeding stuffs has a very high manure value, and maize-meal, which has a very low manure value. The effects of the manures obtained by the consumption of these foods will be compared with those of artificial manures supplying, in one case the same amount of nitrogen, potass, phosphoric acid, \&c., as is estimated to be contained in the manure from the cottoncake consumed, and in another the same as in that from the maize-meal consumed. Accordingly, four feeding experiments have been conducted, in each of which the same amount of litter has been used, and the same amount of roots, and the same amount of wheat-straw chaff consumed. In Experiment I, I,Ooo lbs. decorticated cotton-cake were given in addition; and in Experiment 2, 1,000 lbs. maizemeal. In Experiments 3 and 4 no purchased food was given; but in Experiment 3 artificial manures estimated to contain the same amount of the chief constituents as the manure from $I, 000$ lbs. of cotton-cake, and in Experiment 4 the same as from 1,000 los. maize-meal, will be applied to the land, in addition to the root and chaff manure.

Four areas of four acres each have been devoted to these rotation experiments, eight of them coming into exact experiment this year, and the remaining eight in 1878 . Each area of four acres is again divided into four plots, each of the latter sub-divisions bearing the same crop during the rotation of four years, but undergoing different treatment in the way of manure. For example, rotation No. I, now under seeds, is treated as follows. Each plot is being separately fed by sheep. Plot I with cottoncake; Plot 2 with maize-meal; and Plcts 3 and 4 without purchased food. But, for the succeeding wheat, artificial manure estimated to contain nitrogen, and other constituents, in amounts equal to those in the manure from the consumed cotton-cake, will be applied to Plot 3 , and artificial manure, equal to that from the consumed maizemeal will be applied to Plot 4. For the roots in 1879 (succeeding the wheat), the 4 acres will be manured as already described, and barley will complete the course in 1880 . The ofther rotations are so treated as at the end of the four years to yield a collection of data that must be of the highest value in agricultural chemistry, and therefore to practical agriculture. In a "Statement" as to the objects and plan of the experiment which lies before us, full details are given on all points, and carefully constructed tables relating to every stage of the experiments, which show that all possible care has been taken to secure accuracy and practical utility in the results. The experiment will no doubt be anxiously watched by all interested in scientific agriculture.

\section{NOTES}

Pror. FrankLand, D.C.L., F.R.S., has now in the press a volume containing his collected researches in Pure, Applied, and Physical Chemistry, dedicated to Prof, Bunsen, of Heidelberg. The section on Pure Chemistry treats, amongst other matters, of the Isolation of the Organic Radicals, and the Discovery of Organo-Metallic Bodies, and their A pplication to the Synthetical Production of Organic Compounds. In the section devoted to Applied Chemistry, the author describes his Investi. gations on the Manufacture of Gas for Illuminating Purposes; on the Qualities of Potable Waters; and on the Treatment of the Sewage of Towns. Physical Chemistry includes his Experiments upon Flames, and upon the Source of Muscular Power, together with those on the Spectra of Gases and Vapours. Each chapter is preceded by introductory remarks, having reference to the scope, object, and future development of the subject treated of. Mr. Van Voorst is the publisher.

A MOVEMENT has been commenced in Spain for the formation of an association similar to the British Association. The Madrid Societies of Natural |History, Anthropology, and Geography have appointed a joint commission to consider how best to organise an annual meeting-in different parts of the kingdom for the purpose of investigating matters of scientific interest within the domain of these societies, and also to arrange for the publication of the results that may thus be obtained. A movement 